\title{
PRODUKSI DAN RENDEMEN PENGOLAHAN NILAM (Pogostemon cablin Benth) DARI HUTAN RAKYAT DI DESA BONE-BONE KECAMATAN BARAKA, KABUPATEN ENREKANG
}

\section{(The Production And Yield Of Patchouli Processing (Pogostemon Cablin Benth) From Community Forest In Bone-Bone Village, Baraka Sub District,Enrekang District)}

\author{
M. Daud ${ }^{1)}$, Hikmah ${ }^{1)}$, Hendri ${ }^{2)}$ \\ 1) Program Studi Kehutanan Universitas Muhammadiyah Makassar \\ 2) Alumni Program Studi Kehutanan Universitas Muhammadiyah Makassar \\ email: mdaudhammasa@gmail.com
}

\begin{abstract}
This study aims to determine the production and yield of patchouli processing (Pogostemon cablin Benth) from community forest in Bone-Bone Village, Baraka Sub District, Enrekang Regency. The types of data collected were primary data and secondary data. Primary data was collected by observation, interview, and survey methods while secondary data was collected using literature studies. The results showed that the average production of one-crop patchouli belonging to farmers in community forest in Bone-Bone Village was $430 \mathrm{~kg} / \mathrm{harvest}$ with patchouli land area of 0.29 ha on average, with patchouli harvesting frequency of 2 harvests per year, the average annualproduction patchouli plant was $860 \mathrm{~kg} / y e a r$, patchouli production per harvest per hectare on average was $1,497.28 \mathrm{~kg} / \mathrm{ha}$, productivity of patchouli plants on average was $2,994.55 \mathrm{~kg} / \mathrm{ha}$ per year and the yield of patchouli processing into patchouli oil varies between 2.88-3.19\% with an average yield of $3.00 \%$
\end{abstract}

Kata Kunci: patchouli, patchouli oil, community forest, production, yield

\begin{abstract}
Abstrak
Penelitian ini bertujuan untuk mengetahui produksi dan rendemen pengolahan nilam (Pogestemon cablin Benth) pada hutan rakyat di Desa Bone-Bone Kecamatan Baraka Kabupaten Enrekang. Jenis data yang dikumpulkan adalah data primer dan data sekunder. Data primer dikumpulkan dengan metode observasi, wawancara dan survey sedangkan data sekunder dikumpulkan menggunakan studi literatur. Hasil penelitian menunjukkan bahwa produksi rata-rata tanaman nilam sekali panen milik petani pada hutan rakyat di Desa BoneBone $430 \mathrm{~kg} /$ panen dengan luas lahan tanaman nilam rata-rata 0.29 ha, dengan frekuensi pemanenan nilam 2 kali panen per tahun maka produksi rata-rata tanaman nilam per tahun petani nilam adalah $860 \mathrm{~kg} / \mathrm{tahun}$, produksi nilam sekali panen per hektar rata-rata adalah $1,497.28 \mathrm{~kg} / \mathrm{ha}$, produktivitas tanaman nilam rata-rata adalah $2,994.55 \mathrm{~kg} / \mathrm{ha}$ per tahun serta rendemen pengolahan nilam menjadi minyak nilam bervariasi antara 2.88-3.19\% dengan rendemen rata-rata $3.00 \%$
\end{abstract}

Kata Kunci: Nilam, Minyak Nilam, Hutan Rakyat, Rendemen 


\section{PENDAHULUAN}

Hasil Hutan Bukan Kayu yang selanjutnya disingkat HHBK adalah hasil hutan hayati baik nabati maupun hewani beserta produk turunan dan budidaya kecuali kayu yang berasal dari hutan. Kasmudjo (2011), mengatakan hasil hutan bukan kayu secara garis besar terdiri dari produk nabati dan hewani atau simbiosis keduanya. Untuk hasil hutan bukan kayu nabati bisa dikelompokkan ke dalam kelompok tumbuhan berkekuatan seperti rotan, kelompok rumput-rumputan (terutama bambu) dan kelompok ekstraktif tumbuhan. Kelompok dari ekstraktif tumbuhan menghasilkan bahan ekstraktif yang dapat diperoleh melalui proses ekstraksi, pengepresan dan destilasi (penyulingan). Hasil akhir dari ekstraktif tumbuhan dapat berupa minyak tumbuhan, aneka getahgetahan dan produk ekstrak lainnya seperti bahan penyamak, bahan pewarna alami dan alkaloid (bahan obat-obatan). Setiap produk yang dihasilkan dapat diambil dari berbagai bagian tanaman seperti dari daun, kulit kayu (batang), buah/biji, bunga, akar dan sebagainya. Salah satu hasil hutan bukan kayu yang cukup potensial adalah minyak atsiri.

Minyak atsiri adalah jenis komoditi yang sangat penting di dunia sehingga telah mampu diperdagangkan secara global dengan nilai yang memadai. Minyak atsiri dikenal juga dengan nama minyak eteris atau minyak terbang (essential oil, volatile oil) dihasilkan dari proses ekstraksi semua tanaman. Minyak tersebut bersifat encer, bening (jernih), mudah menguap pada suhu kamar, mempunyai rasa getir (pungent taste), berbau spesifik, larut dalam pelarut organik tetapi tidak larut dalam air (Kasmudjo 2011).

Setiap tahun konsumsi minyak atsiri dunia beserta turunannya naik sekitar 8-10\% (Untung 2009). Kenaikan itu disebabkan karena masyarakat sudah mulai menyadari akan pentingnya minyak atsiri untuk industri parfum, kosmetik dan kesehatan. Selain itu pola pikir masyarakat yang sudah mulai berubah untuk mengkonsumsi bahan-bahan senyawa sintetik ke bahan alami turut menjadikan permintaan minyak atsiri meningkat.Salah satu tanaman yang menghasilkan minyak atsiri potensial dikembangkan di Indonesia adalah nilam. Tanaman nilam merupakan salah satu tanaman penghasil minyak atsiri yang cukup penting sebagai komoditi ekspor Indonesia dan menyumbang devisa sekitar $60 \%$ dari total ekspor minyak atsiri nasional (Setya et al. 2012).

Indonesia merupakan pemasok minyak nilam terbesar dunia dengan kontribusi $70 \%$ (Nuryani 2006). Namun, ekspor minyak nilam cenderung menurun dari tahun ke tahun. Penyebab penurunan tersebut antara lain rendahnya genetik tanaman, teknologi budidaya yang masih sederhana, berkembangnya berbagai penyakit, serta teknik panen dan pasca panen yang belum tepat, sehingga kemampuan produksi Indonesia untuk minyak nilam terbatas.

Minyak Nilam merupakan hasil hutan bukan kayu yang yang terkenal di Desa Bone-Bone, Kecamatan Baraka, Kabupaten Enrekang. Selain kopi arabika, tanaman nilam merupakan komoditas utama masyarakat Desa Bone-Bone.Tanaman nilam di daerah ini dianggap menghasilkan minyak nilam kualitas baik karena tumbuh pada daerah yang kurang terpapar polusi udara. Hasil dari minyak nilam ini telah dipasarkan sampai keluar negeri. Desa Bone-bone yang terletak diatas ketinggian $1.500 \mathrm{~m} / \mathrm{dpl}$ itu telah membuat peraturan desa (Perdes) nomor 1 tahun 2009 tentang Kawasan Bebas Asap Rokok. Penelitian ini bertujuan untuk mengetahui produksi dan rendemen pengolahan nilam (Pogostemon cablin Benth) dari hutan rakyat diDesa Bone-Bone Kecamatan Baraka Kabupaten Enrekang. 
Volume 1 Nomor 1 Juli 2019: 9-15

\section{METODOLOGI PENELITIAN}

Penelitian ini dilaksanakan dalam waktu kurang lebih 2 (dua) bulan yaitu September - November 2018 di Desa Bonebone Kecamatan Baraka Kabupaten Enrekang. Alat dan bahan yang digunakan dilapangan untuk penelitian ini adalah alat tulis menulis, quisioner, kamera, timbangan dan meteran roll.

Adapun data yang digunakan terdiri atas data primer dan data sekunder. Data Primer adalah data yang di peroleh melalui observasi langsung di lapangan dan wawancara dengan responden yang berada di Desa Bone-bone Kecamatan Baraka Kabupaten Enrekang yang terlibat langsung dalam proses produktivitas tanaman nilam. Data sekunder berupa data yang diperoleh dari laporan-laporan kantor Desa dan Kecamatan serta instansi-instansi terkait Dinas Kehutanan dan pusat statistik untuk memperoleh informasi seperti data sosial, ekonomi penduduk, dan keadaan umum lokasi.

Teknik Pengumpulan data primer sebagai berikut :

\section{Observasi}

Observasi adalah salah satu metode pengumpulan data dengan mengamati secara langsung dilokasi penelitian atau lapangan.

2. Wawancara

Wawancara adalah metode pengumpulan data dengan cara tanya jawab untuk mendapatkan informasi yang dibutuhkan.

3. Metode Quisioner

Metode quisioner adalah metode pengumpulan data dengan cara memberikan daftar pertanyaan kepada responden untuk mendapatkan informasi yang dibutuhkan.

4. Metode Survey

Metode survey dilakukan dengan melakukan penimbangan berat tanaman nilam yang dipanen oleh petani serta melalukan penimbangan berat minyak nilam yang dihasilkan setelah penyulingan.
Selanjutnya, data yang telah dikumpulkan dianalisis dengan menggunakan rumus sebagai berikut.

a. Produksi Tanaman Nilam Per Tahun

$$
\begin{aligned}
& P N T \\
& =P N S P \times F p
\end{aligned}
$$

Keterangan:

PNT:Produksi Tanaman Nilam Per Tahun (kg per Tahun)

PNSP: Produksi Tanaman Nilam Sekali Panen (kg/panen)

Fp :Frekuensi pemanenan Nilam Selama Setahun (kali per tahun)

b. Produksi Tanaman Nilam Per Hektar

$$
P N H=\frac{P N S P}{L}
$$

PNH: Produsi Tanaman NilamPer $\mathrm{Ha}(\mathrm{kg} / \mathrm{ha}$ per Tahun)

PNSP: Produksi Tanaman Nilam Sekali Panen (kg/panen)

L : Luas Lahan Nilam (ha)

c. Produktivitas Nilam

$$
P t N=\frac{P N S P x F p}{L}
$$

PtN: Produktivitas Tanaman Nilam/ha Per Tahun (kg per Tahun)

PNSP: Produksi Tanaman Nilam Sekali Panen (kg/panen)

Fp : $\quad$ Frekuensi Pemanenan Nilam Selama Setahun (kali per tahun)

L : Luas Lahan Nilam (ha)

d. Rendemen Minyak Nilam

$$
R=\frac{P M N S P}{P N S P} \times 100 \%
$$

$\mathrm{R}$ : Rendemen Minyak Nilam (\%)

PMNSP: Produksi Minyak Nilam Sekali Panen (kg/panen)

PNSP: Produksi Tanaman Nilam Sekali Panen (kg/panen) 


\section{HASIL DAN PEMBAHASAN}

\section{A. Identitas Petani Nilam}

Identitas petani nilam merupakan keadaan yang menggambarkan kondisi umum dari responden masayrakat petani nilam yang masih aktif. Identitas petani nilam yang dikaji dalam penelitian inimeliputi: umur, tingkat pendidikan, dan jumlah tanggungan anggota keluarga.

\section{Umur Responden}

Tabel 1. Kelompok Umur Petani Nilam

\begin{tabular}{|c|c|c|c|}
\hline No. & $\begin{array}{l}\text { Kelompok } \\
\text { usia } \\
\text { (umur) }\end{array}$ & $\begin{array}{l}\text { Jumlah } \\
\text { responden }\end{array}$ & $\begin{array}{l}\text { Persentase } \\
(\%)\end{array}$ \\
\hline 1 & $15-34$ & 2 & 15,39 \\
\hline 2 & $35-54$ & 10 & 76,92 \\
\hline 3 & 54-65 & 1 & 7,69 \\
\hline & Jumlah & 13 & 100,00 \\
\hline
\end{tabular}

Sumber : Data Primer Setelah Diolah, 2018.

Tabel 1 menunjukkan bahwa usia petani pada umumnya sekitar 35 - 54tahun dengan persentase $(76.92 \%)$ dengan jumlah10 orang, usia kelompok umur 15 34 tahun dengan persentase $(15.39 \%)$ dengan jumlah 2 orang sedangkan kelompok umur di atas 54 tahun mempunyai persentase $(7.69 \%)$ dengan jumlah 1 orang. Hal ini menunjukkan bahwa petani nilam sangat diminati oleh usia produktif tua. Dikatakan usia produktif karena responden diasumsikan memiliki kemampuan baik, kemampuan berfikir maupun kemampuaan fisik yang kuat, pengalaman yang baik, dan masih mampu untuk bekerja sehingaa nantinya mereka dapat meningkatkan pendapatan.

\section{Tingkat Pendidikan Responden}

Pendidikan sangat penting untuk dimiliki seseorang. Tingkat pendidikan seseorang akan mempengaruhi dalam mengelolah usaha mereka untuk
Komposisi Penduduk berdasarkan umur dikelompokan menjadi tiga :

1) Kelompok Umurproduktif muda 15 34Tahun

2) Kelompok Umur produktif tua 35 54Tahun

3) Kelompok Umur yang tidak produktif 54 - 65Tahun

Klasifikasi berdasarkan umur responden,untuk lebih jelasnya dapat dilihat pada Tabel 1 berikut:

meningkatkan jumlah produksi dan juga pendapatannya. Tingkat pendidikan dan besar pendapatan seseorang juga mempunyai hubungan satu sama lain. Semakin tinggi pendidikan seseorang, maka semakin banyak pula pengetahuan dan pengalaman yang di peroleh, sehingga mereka mampu untuk menerapkan dalam kehidupan terutama dalam mengelolah hutan, untuk lebih jelasnya dapat dilihat pada Tabel 2 berikut:

Tabel 2. Tingkat Pendidikan Pendidikan Petani Nilam

\begin{tabular}{|l|l|l|c|}
\hline No. & $\begin{array}{l}\text { Tingkat } \\
\text { Pendidikan }\end{array}$ & $\begin{array}{l}\text { Jumlah } \\
\text { Responden } \\
\text { (Orang) }\end{array}$ & $\begin{array}{l}\text { Persentase } \\
(\%)\end{array}$ \\
\hline 1 & SD & 1 & 30.76 \\
2 & SMP & 7 & 7.69 \\
3 & SMA & 4 & 53.84 \\
4 & SARJANA & 1 & 30.76 \\
\hline & Jumlah & 13 & 100.00 \\
\hline
\end{tabular}

Sumber : Data Primer Setelah Diolah, 2018.

Berdasarkan Tabel 2 menunjukkan bahwa dari 13 orang responden, di Desa Bone-Bone Kecamatan Baraka Kabupaten Enrekang yang tamat SD sebanyak 1 orang responden, tingkat SMP sebanyak 7 orang responden, tingkat SMA sebanyak 4 orang responden, sarjana sebanyak 1 orang responden. 
Tabel 3. Luas Lahan Responden

\begin{tabular}{|l|l|l|}
\hline No & Nama Petani Nilam & Luas Lahan Tanaman Nilam (Ha) \\
\hline 1 & Rudianto & 0.45 \\
2 & Rahmat & 0.36 \\
3 & Suadi & 0.21 \\
4 & Herman & 0.60 \\
5 & Batton & 0.36 \\
6 & Amiruddin & 0.32 \\
7 & Kadang & 0.50 \\
8 & Nur.Inna & 0.08 \\
9 & Basri & 0.14 \\
10 & Sukriani & 0.24 \\
11 & Ruslan & 0.15 \\
12 & Ny Nipa & 0.25 \\
13 & TifeS.Pdi & 0.06 \\
\hline Jumlah & 3.72 \\
\hline \multicolumn{2}{|l|}{ Rata-Rata } & 0.29 \\
\hline
\end{tabular}

Sumber : Data Primer Setelah Diolah, 2018.

\section{Luas Lahan Tanaman Nilam Petani}

Luas lahan tanaman nilam yang dikelolah petani tidak terlalu luas dan semuanya kurang dari 1 ha. Luas lahan tanaman nilam petani dapat dilihat pada Tabel 3.

\section{B. Produksi dan Rendemen Pengolahan Nilam}

Proses produksi nilam di Desa Bonebone Kecamatan Baraka Kabupaten Engrekang dalam proses produksi nilam masih menggunakan cara sederhana, mulai dari tahap penanaman sampai tahap pemanenan. Peroses pemanenan nilam dilakukan pada usia 6-7 bulan untuk pemanenan pertama dan dapat dipanen kembali 3-4 bulan selajutnya. Nilam yang sudah dipanen kemudian dicacah kecil-kecil untuk memudahkan penyulingan kemudian dijemur sampai kering untuk menghilangkan kadar air yang terdapat pada tanaman nilam kemudian nilam yang sudah kering disuling menggunakan tungku khusus selama 8-9 jam.

Berdasarkan tabel 4 diatas dapat di lihat bahwa produksi nilam sekali panen bervariasi antara 80-870 kg/panen dengan rata-rata produksi $430 \mathrm{~kg} /$ panen. Jumlah frekuensi pemanen nilam adalah 2 kali dalam setahun sehingga produksi tanaman nilam yang dapat dipanen dalam setahun oleh petani adalah bervariasi antara 160-1,740 $\mathrm{kg} /$ tahun dengan rata-rata produksi 8,600 $\mathrm{kg} / \mathrm{tahun}$. Perbedaan produksi ini disebabkan oleh perbedaan produksi nilam dan luas lahan nilam setiap petani. Luas lahan petani bervariasi antara 0.06-0.6 ha dengan rata-rata 0.29 ha.

Produksi tanaman nilam sekali panen per hektar berkisar antara 1,250-1,904.76 $\mathrm{kg} / \mathrm{ha}$ dengan rata-rata $1,497.28 \mathrm{~kg} / \mathrm{ha}$. Produktivitas tanaman nilam adalah 2,500.00-3,809.52 $\mathrm{kg} / \mathrm{ha}$ per tahun dengan rata-rata $2,994.55 \mathrm{~kg} / \mathrm{ha}$. 
Tabel 4. Produksi dan Rendemen Pengolahan nilam padaHutan Rakyat di Desa Bone-Bone Kecamatan Baraka Kabupaten Enrekang

\begin{tabular}{|c|c|c|c|c|c|c|c|c|c|}
\hline No. & $\begin{array}{c}\text { Nama } \\
\text { petani }\end{array}$ & $\begin{array}{c}\text { Produksi } \\
\text { Nilam } \\
\text { Per } \\
\text { panen } \\
(\mathrm{kg})\end{array}$ & $\begin{array}{c}\text { Minyak } \\
\text { Nilam } \\
(\mathrm{kg})\end{array}$ & $\begin{array}{c}\text { Frekuensi } \\
\text { Panen } \\
\text { Per } \\
\text { Tahun } \\
\text { (Kali/Tah } \\
\text { un) }\end{array}$ & $\begin{array}{c}\text { Luas } \\
\text { Lahan } \\
\text { Nilam } \\
\text { (ha) }\end{array}$ & $\begin{array}{c}\text { Produksi } \\
\text { Nilam Per } \\
\text { Tahun } \\
\text { (kg/Tahun) }\end{array}$ & $\begin{array}{c}\text { Produksi } \\
\text { Nilam } \\
\text { Sekali } \\
\text { Panen } \\
\text { Per } \\
\text { Hektar } \\
\text { kg/ha) }\end{array}$ & $\begin{array}{c}\text { Produkti } \\
\text { vitas } \\
\text { Nilam } \\
\text { (kg/ha } \\
\text { per } \\
\text { Tahun) }\end{array}$ & $\begin{array}{c}\text { Ren } \\
\text { dem } \\
\text { en } \\
(\%)\end{array}$ \\
\hline 1 & Rudianto & 700.00 & 21.00 & 2.00 & 0.45 & $1,400.00$ & $1,555.56$ & $3,111.11$ & 3.00 \\
\hline 2 & Rahmat & 500.00 & 15.00 & 2.00 & 0.36 & $1,000.00$ & $1,388.89$ & $2,777.78$ & 3.00 \\
\hline 3 & Suadi & 400.00 & 12.00 & 2.00 & 0.21 & 800.00 & $1,904.76$ & $3,809.52$ & 3.00 \\
\hline 4 & Herman & 870.00 & 26.00 & 2.00 & 0.60 & $1,740.00$ & $1,450.00$ & $2,900.00$ & 2.99 \\
\hline 5 & Batton & 560.00 & 16.80 & 2.00 & 0.36 & $1,120.00$ & $1,555.56$ & $3,111.11$ & 3.00 \\
\hline 6 & Amiruddin & 450.00 & 13.50 & 2.00 & 0.32 & 900.00 & $1,406.25$ & $2,812.50$ & 3.00 \\
\hline 7 & Kadang & 720.00 & 21.60 & 2.00 & 0.50 & $1,440.00$ & $1,440.00$ & $2,880.00$ & 3.00 \\
\hline 8 & Nur Inna & 100.00 & 2.88 & 2.00 & 0.08 & 200.00 & $1,250.00$ & $2,500.00$ & 2.88 \\
\hline 9 & Basri & 200.00 & 6.00 & 2.00 & 0.14 & 400.00 & $1,428.57$ & $2,857.14$ & 3.00 \\
\hline 10 & Sukriani & 430.00 & 12.90 & 2.00 & 0.24 & 860.00 & $1,791.67$ & $3,583.33$ & 3.00 \\
\hline 11 & Ruslan & 240.00 & 7.20 & 2.00 & 0.15 & 480.00 & $1,600.00$ & $3,200.00$ & 3.00 \\
\hline 12 & Ny Nipa & 340.00 & 10.20 & 2.00 & 0.25 & 680.00 & $1,360.00$ & $2,720.00$ & 3.00 \\
\hline 13 & Tife & 80.00 & 2.55 & 2.00 & 0.06 & 160.00 & $1,333.33$ & $2,666.67$ & 3.19 \\
\hline & Jumlah & $5,590.00$ & 167.63 & 26.00 & 3.72 & $11,180.00$ & $19,464.58$ & $38,929.1$ & 39.0 \\
& & & & & & & & 7 & 6 \\
\hline & Rata-Rata & 430.00 & 12.89 & 2.00 & 0.29 & 860.00 & $1,497.28$ & $2,994.55$ & 3.00 \\
\hline
\end{tabular}

Sumber : Data Primer Setelah Diolah, 2018.

Hasil penelitian ini menunjukkan bahwa produktivitas nilam pada Hutan Rakyat di Desa Bone-Bone Kecamatan Baraka Kabupaten Enrekang lebih rendah dibandingkan produktivitas nilam rata-rata dari hasi penelitian Nuryani (2006) yaitu sekitar 4-5 ton/ha per tahun, bahkan beberapa varietas dapat mencapai 10.90 ton/ha per tahun untuk varietas Sidikalang, 11.09 ton/ha per tahun varietas Lhokseumawe, dan 13.28 ton/ha per tahun varietas Tapak Tuan.

Rendemen Pengolahan nilam menjadi minyak nilam pada Hutan Rakyat di Desa Bone-Bone Kecamatan Baraka Kabupaten Enrekang berkisar antara 2.88 -3.19\% dengan rata-rata $3.00 \%$. Menurut Nuryani, et al. (1997), rendemen minyak bervariasi antara 1.6- $3.59 \%$ tergantung dari varietasnya. Tanaman nilam adalah tanaman penghasil minyak atsiri, oleh karena itu produksi, rendamen minyak dan mutu minyak merupakan faktor penting yang dapat dipergunakan untuk menentukan keunggulan sebuah varietas. Di samping itu, karakter lainnya seperti sifat ketahanan terhadap penyakit juga merupakan salah satu indikator penentu. Banyak faktor yang mempengaruhi kadar dan mutu minyak nilam antara lain genetik (jenis), budidaya, lingkungan, panen dan paska panen. 
Volume 1 Nomor 1 Juli 2019: 9-15

\section{KESIMPULAN DAN SARAN}

Berdasarkan hasil penelitian produksi dan rendemen pengolahan nilam pada hutan rakyat di Desa Bone-Bone Kecamatan Baraka Kabupaten Enrekang, maka dapat dirumuskan kesimpulan sebagai berikut :

1. Produksi rata-rata tanaman nilam sekali panen milik petani nilam pada hutan rakyat di Desa Bone-Bone, Kecamatan Baraka, Kabupaten Enrekang adalah430 $\mathrm{kg} /$ panen dengan luas lahan rata-rata 0.29 ha, dengan frekuensi pemanenan nilam 2 kali setahun makaproduksi nilam rata-rata per tahun adalah $860 \mathrm{~kg} /$ tahun, produksi rata-rata nilam sekali panen per hektar adalah 1,497.28 $\mathrm{kg} / \mathrm{ha}$ sedangkan produktivitas rata-rata tanaman nilam adalah $2,994.55 \mathrm{~kg} / \mathrm{ha}$ per tahun.

2. Rendemen minyak nilam pada hutan rakyat di Desa Bone-Bone, Kecamatan Baraka, Kabupaten Enrekang berkisar antara 2.88-3.19\% dengan rata-rata 3.00\%

Tanaman nilam sangat berpotensi dikembangkan dalam hutan rakyat karena dapat meningkatkan kesejahteraan petani, meskipun demikian metode penyulingan yang dilakukan masih sederhana sehingga perlu diberi input teknologi untuk meningkatkan rendemen dan mutu minyak nilam yang dihasilkan.

\section{DAFTAR PUSTAKA}

Kasmudjo, S. 2011. Hasil Hutan Non Kayu.Padang Sumatra Barat. Cakrawala Media 2011

Nuryani, Y. 2006. Budidaya Tanaman Nilam (Pogostemon calbin Benth. Balai penelitian Tanaman Rempah dan Aromatik, Bogor

Nuryani, Y., C. Syukur, dan D. Rukmana. 1997. Evaluasi dan dokumentasi Klonklon harapan Nilam. Balai

penelitian Tanaman Rempah dan Aromatik, Bogor

Setya, N. H., Budiarti, A., dan Mahfud. 2012. Proses pengambilan minyak atsiri dari daun nilam dengan pemanfaatan gelombang mikro (Microwave). Jurnal Teknik ITS. 1 (1). 25-29.

Untung, O. 2009. Minyak Atsiri. Vol 07. PT Trubus Swadaya, Jakarta 